INSTRUMENTATION FOR MEASUR ING LAKE

AND RESERVOIR EVAPORATION BY THE

ENERGY-BUDGET AND MASS-TRANSFER METHODS

BY ALEX M. STURROCK, JR .

U.S . GEOLOGICAL SURVEY

Open-File Report 84-863

NSTL, MISSISSIPPI 1985 
UNITED STATES DEPARTMENT OF THE INTER IOR

WILLIAM P. CLARK, Secretary

GEOLOGICAL SURVEY

Dallas L. Peck, Director

For additional information write to:

Copies of this report

can be purchased from:

Chief, Hydrologic Instrumentation Facility U.S. Geological Survey, B1dg. 2101 NSTL, MS 39529

Open-File Services Section Western Distribution Branch Box 25425, Federal Center Denver, CO 80225

(Telephone: (303) 234-5888) 
CONTENTS

Page

Abstract $\ldots \ldots \ldots \ldots \ldots \ldots \ldots \ldots \ldots \ldots \ldots \ldots \ldots \ldots \ldots \ldots \ldots \ldots \ldots \ldots$

Introduction $\ldots \ldots \ldots \ldots \ldots \ldots \ldots \ldots \ldots \ldots \ldots \ldots \ldots \ldots \ldots \ldots \ldots \ldots$

Energy-Budget Instrumentation $\ldots \ldots \ldots \ldots \ldots \ldots \ldots \ldots \ldots \ldots \ldots \ldots$

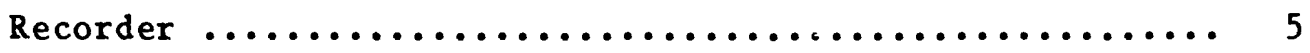

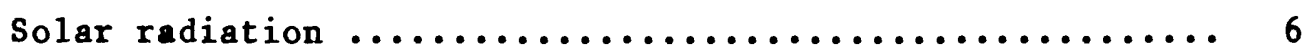

Reflected solar radiation $\ldots \ldots \ldots \ldots \ldots \ldots \ldots \ldots \ldots \ldots . \ldots \ldots$

Long-wave radiation $\ldots \ldots \ldots \ldots \ldots \ldots \ldots \ldots \ldots \ldots \ldots \ldots$

Reflected long-wave radiation $\ldots \ldots \ldots \ldots \ldots \ldots \ldots \ldots \ldots$

Long-wave radiation emitted by a body of water ........ 10

Net energy advected to a body of water............... 11

Heat transfer between the water and the bottom

sediments $\ldots \ldots \ldots \ldots \ldots \ldots \ldots \ldots \ldots \ldots \ldots \ldots \ldots \ldots \ldots \ldots \ldots \ldots$

Change in energy content of a body of water $\ldots \ldots \ldots \ldots 12$

Vapor pressure ............................ 12

Mass-Transfer Instrumentation ..................... 15

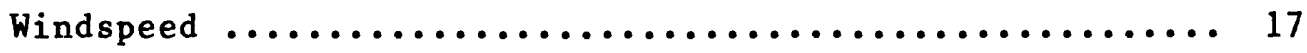

References $\ldots \ldots \ldots \ldots \ldots \ldots \ldots \ldots \ldots \ldots \ldots \ldots \ldots \ldots \ldots \ldots \ldots \ldots$

List of Figures

$\begin{array}{ll}\text { Figure } & \text { Page }\end{array}$

1. Recording system showing the printer, micrologger,

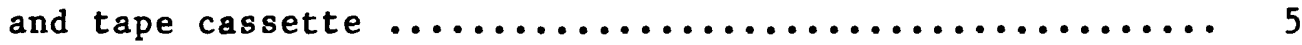


2. Eppley PSP showing clear glass domes, guard disc, desiccator, spirit level, and leveling screws ......... 7

3. Eppley PIR showing silicone hemisphere, guard disc, desiccator, spirit level, and leveling screws ......... 10

4. Whitney underwater thermometer $\ldots \ldots \ldots \ldots \ldots \ldots \ldots \ldots \ldots$

5. Complete thermistor psychrometer, with tetraskelion shield, showing (top to bottom) hat, dry-bulb temperature section, wet-bulb temperature section, and reservoir ........... 15

6. Psychrometer unit showing (top to bottom) dry-bulb temperature sensor, wick covering wet-bulb temperature sensor, and plastic reservoir .................. 15

7. Raft station showing anemometers and thermistor psychrometers at multiple levels ................... 18 
INSTRUMENTATION FOR MEASURING LAKE AND RESERVOIR EVAPORATION

BY THE ENERGY-BUDGET AND MASS-TRANSFER METHODS

by Alex M. Sturrock, Jr.

\begin{abstract}
Instrumentation currently used by the U.S.

Geological Survey in studies of evaporation from lakes and reservoirs is described in this paper. This instrumentation is used for the measurement of solar and terrestrial energy necessary to apply the mass-transfer or energy-budget methods. The energy-budget method requires a quantitative determination of all forms of energy entering or leaving the lake, as well as determination of the change in storage of energy within the lake.
\end{abstract}

\title{
INTRODUCTION
}

At present, there are four commonly used methods of determining evaporation from a body of water. The four methods are: water-budget, evaporation-pan, energy-budget, and mass-transfer. This report is limited to the discussion of the instrumentation used by the U.S. Geological Survey for the energy-budget and mass-transfer methods to determine evaporation losses from lakes and reservoirs.

The energy-budget method requires a calculation to determine values for parameters of reflected solar and long-wave radiation, effective back radiation, energy advected into or out of the water body, energy stored in the water body, and the rates of energy used for evaporation to the energy conducted as sensible heat to the atmosphere. 
The other parameters of incoming solar and long-wave radiation, vapor pressure of the air, and water surface temperature are evaluated directly from measurements made with a pyranometer, a pyrgeometer, a nonventilated psychrometer, and a waterproof thermistor.

For the mass-transfer method, estimations of evaporation are obtained from measurement of water surface temperature, as well as wetand dry-bulb temperatures and windspeeds at one or more levels above the water surface.

In the development and selection of instrumentation for lake and reservoir evaporation studies, it is necessary to consider the following limitations:

1. The station located in the middle of a lake or reservoir will not be served by power lines, so all power must be supplied by batteries .

2. It may not be practical to visit a station more frequently than once a week, so instruments must operate unattended for at least that period of time.

3. The accuracy of measurement is important, so instruments must maintain their calibrations.

At each study site, instrumentation to measure lake and reservoir evaporation for the energy-budget and mass-transfer methods, are operated concurrently at both land station and raft station locations.

The land stations are located on or near the lake or reservoir shoreline. The instrumentation here includes a pyranometer and pyrgeometer for measurement of the incoming radiation parameters for the energy-budget method. It also includes a supplemental wet- and drythermistorized psychrometer that serves as a backup record for the primary psychrometer located on the raft. 
The raft stations are located over the original river channels near tributaries and at the extreme ends of the river reservoirs, and also, at or near the center of circular and irregularly shaped lakes.

The instrumentation for the raft stations includes the water surface temperature sensors and thermistorized psychrometer sensors, used in both the energy-budget and mass-transfer methods, along with an anemometer to record windspeed for the mass-transfer equation.

At lake and reservoir study sites, the number of land and raft stations will vary according to the lake or reservoir size.

\section{ENERGY-BUDGET INSTRUMENTATION}

The energy budget for a lake or reservoir may be expressed as follows :

$$
Q \mathbf{Q}-Q \mathbf{r}+Q_{a}-Q \mathbf{a r}-Q_{b s}+Q \mathbf{v}-Q e-Q h-Q w+Q b=Q x
$$

where

$$
\begin{aligned}
& Q_{\mathbf{s}}=\text { incoming solar radiation incident to the water surface, } \\
& Q_{\mathbf{r}}=\text { reflected solar radiation, } \\
& Q_{\mathbf{a}}=\text { incoming long-wave radiation from the atmosphere, } \\
& Q_{\mathbf{a r}}=\text { reflected long-wave radiation, } \\
& Q_{\mathbf{b}}=\text { long-wave radiation emitted by the body of water, } \\
& Q_{\mathbf{v}}=\text { net energy adverted to the body of water, } \\
& Q_{\mathbf{e}}=\text { energy used for evaporation, }
\end{aligned}
$$




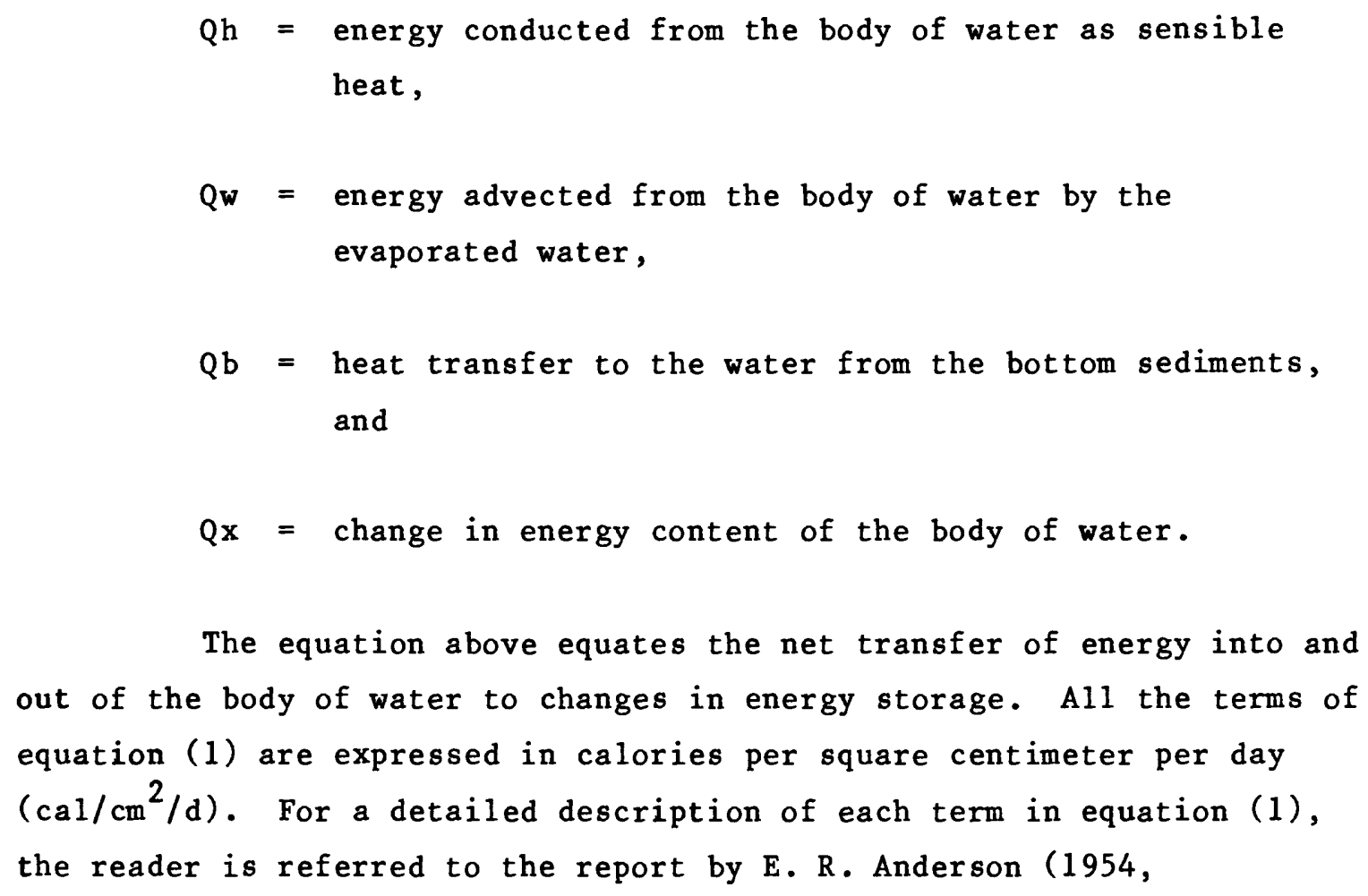

The equation above equates the net transfer of energy into and out of the body of water to changes in energy storage. All the terms of equation (1) are expressed in calories per square centimeter per day $\left(\mathrm{cal} / \mathrm{cm}^{2} / \mathrm{d}\right)$. For a detailed description of each term in equation (1), the reader is referred to the report by E. R. Anderson (1954, p. 71-119).

The energy values for the evaporation process and the sensible-heat exchange between the air and a water surface are not measured directly. Instead, these values are determined using the following equation:

$$
Q \mathbf{s}-Q \mathbf{r}+Q \mathbf{a}-Q \mathbf{a r}-Q b s+Q \mathbf{v}+Q b-Q \mathbf{x}=Q \mathbf{Q}+Q \mathbf{h}+Q \mathbf{w}
$$

The terms on the left side of the equation are measured directly or computed using theoretical or empirical methods. The three terms on the right side of equation (2), $Q e, Q h$, and $Q w$, are not measured directly and are determined as functions of the evaporation rate, which will not be discussed in this report. 


\section{$\underline{\text { Recorder }}$}

Since early 1980, the CR21 Micrologger ${ }^{1}$, made by Campbell Scientific, Inc., has been used to measure the sensor outputs for energy-budget and mass-transfer evaporation studies. The CR21 is a battery-powered microcomputer with a real-time clock, a serial data interface, and a programmable analog-to-digital converter. This 9-channel recorder handles as many as seven analog and two pulsecounting inputs, and once each minute samples the input signals, and processes and stores these data according to the output program specified in the user-entered output table. The data are transferred, for final storage, through a 9-pin connector from the micrologger to a magnetic tape cassette recorder and hard-copy printer supplied by Campbe11 Scientific, Inc. (fig. 1).

For each measured parameter at the land and raft stations, the micrologger is programmed to output averages and/or totals of hourly and

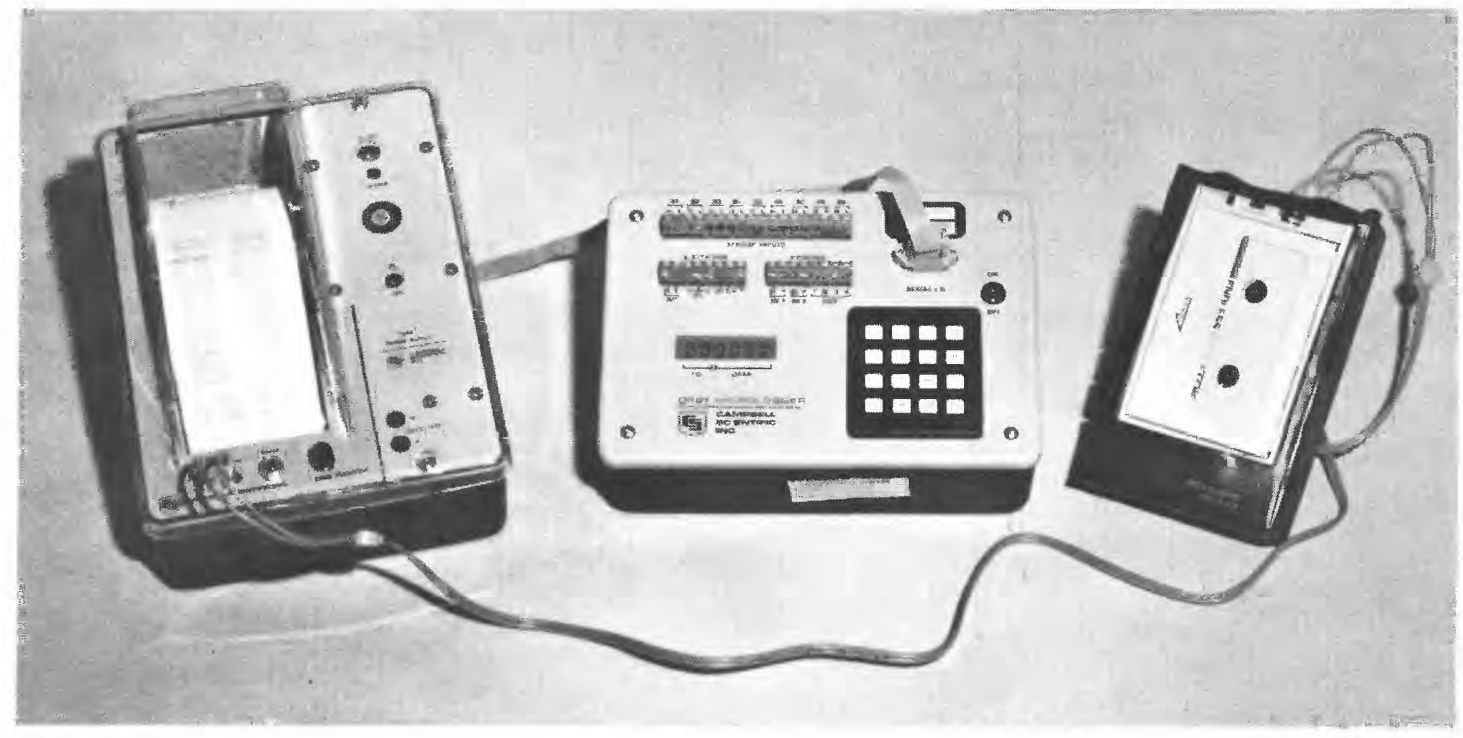

Figure 1. Recording system showing the printer, micrologger, and tape cassette.

$1_{\text {The use of brand names in this report is for identification purposes }}$ only and does not imply endorsement by the U.S. Geological Survey. 
daily values, plus the hourly and daily maximum and minimum values, and the times of occurrence for both.

At each visit to the 1 and and raft stations, the battery voltage of the micrologger, printer, and cassette should be checked. The batteries should be changed if the voltage checks indicate they are below the range specified by the manufacturer. During these visits, current sensor values can be verified by interrogating the micrologger and comparing its current values to secondary sensors carried by the observer to monitor this comparative sensor check. The micrologger, printer, and cassette are housed inside weatherproof shelters at both the land and raft stations.

\section{Solar Radiation}

The Eppley Precision Spectral Pyranometer (PSP) is used in current U.S. Geological Survey lake and reservoir evaporation studies to measure solar radiation on a horizontal surface (fig. 2). This instrument uses an electroplated copper, constantan, wirewound thermopile sensor, coated with Parson's black lacquer. The PSP is enclosed under a pair of removable, precision ground, and polished concentric hemispheres of Schott's clear optical glass. The pyranometer, housed in a cast bronze case, is supplied with the following:

- Built-in desiccator to prevent condensation on the inner surfaces,

- Spirit level and leveling screws, and

- Guard disc to prevent radiation below from reaching the thermopile.

Various types of pyranometers are classified, by the Commission for Instruments and Methods of Observation of the World Meteorological Organization (WMO), as first class, second class, and third class according to the following criteria: sensitivity, 


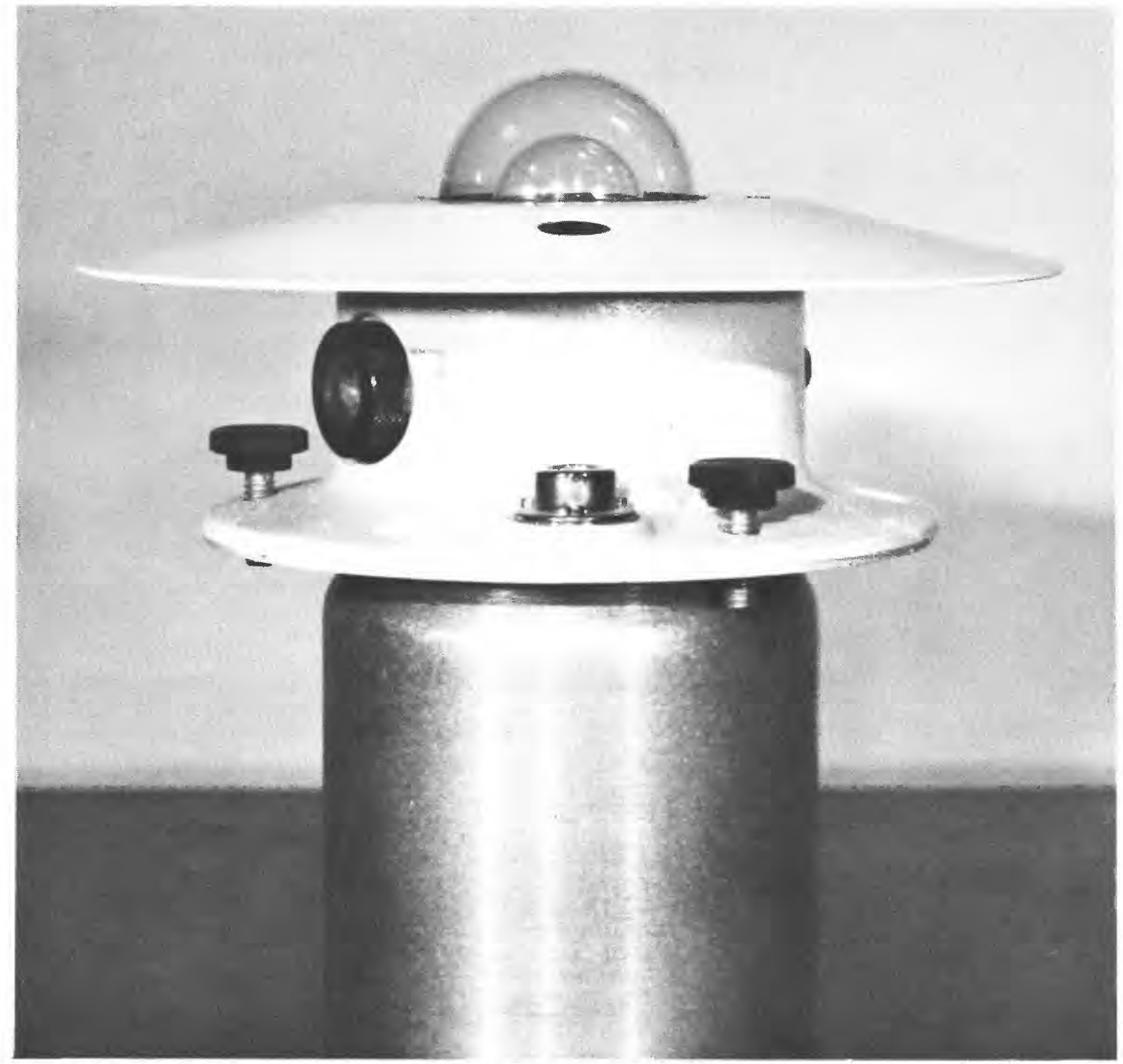

Figure 2. Eppley PSP showing clear glass domes, guard disc, desiccator, spirit level, and leveling screws.

stability, temperature, selectivity, linearity, time constant, cosine response, and azimuth response. The PSP has a WMO first-class instrument rating.

When installing the pyranometer at the field site, the instrument should be located: 
- So that it will be free of any obstructions above the plane of the sensing element, and

- So that a shadow will not be cast upon it at any time.

The pyranometer is oriented with the emerging leads located north of the receiving surface (in the Northern Hemisphere), and is leveled with the aid of the leveling screws and spirit level. A twin conductor (AWG no. 20) waterproofed cable is employed to connect the pyranometer to its recorder.

Because radiation measurements must be made by a stable horizontal pyranometer, radiometers should be installed on the shorelines of lakes and reservoirs rather than on pitching rafts. A flat roof provides the best location for mounting a pyranometer. If such a site cannot be obtained, a rigid stand with a horizontal top surface should be used.

Pyranometers hould be inspected, ideally, once a day. If this condition cannot be met, the less frequent inspection should consist of wiping the outer hemisphere clean and dry with a soft, lint-free cloth; checking the spirit level; and checking the condition of the desiccator installed in the pyranometer case. If the silica gel drying agent is pink or white in color, it should be replaced.

\section{Reflected Solar Radiation}

A part of the solar radiation, incident to the water surface, is reflected back to the atmosphere. The ratio of the reflected solar radiation to incoming solar radiation, the reflectivity, is independent of both windspeed and turbidity and depends primarily upon sun altitude and cloud cover. In present lake and reservoir evaporation studies, reflected solar radiation is determined indirectly from measurements of incoming solar radiation using relationships developed by Koberg (1964, fig. 36). The approximate range in values of reflected solar radiation 
is from 6 percent of the incoming solar radiation during the summer to about 10 percent during the winter.

\section{Long-Wave Radiation}

The techniques for, and problems of, measuring long-wave (or atmospheric) radiation are somewhat different from those measuring solar radiation. The more complex atmospheric regime is largely a result of the emission and absorption of long-wave radiation by real materials-solids, liquids, and gases that make up the physical system of interest.

\section{Long-wave (infrared) radiation is measured by a variety of} instruments called radiometers. Two general types of radiometers are: spectral radiometers (pyrgeometers) that measure the radiation intensity at each wavelength, and nonspectral radiometers (pyrradiometers) that measure the total radiation received from a broad wavelength band. The radiometer currently used by the U.S. Geological Survey for lake and reservoir evaporation studies is the Eppley Precision Infrared Radiometer (PIR). The PIR is a spectral radiometer that measures only the incoming long-wave component of radiation on a horizontal surface (fig. 3). This pyrgeometer was developed from the Eppley Precision Spectral Pyranometer. It uses the same type of wirewound, plated, nonwavelength-selective, thermopile detector and cast bronze case, with a built-in desiccator, as the PSP Model. A thermistor battery-resistance circuit (in addition to that employed for temperature compensation of radiometer response) is incorporated to precisely compensate for detector temperature. To isolate the atmospheric long-wave radiation from the solar short-wave radiation during the daytime, the glass hemisphere of the PSP has been replaced with a silicone hemisphere with vacuumdeposited interference filter on its inner surface. The composite transmission of this pyrgeometer window is approximately 4 to 50 micrometers.

The installation and maintenance procedures for the pyrgeometer follow the same instructions given for the pyranometer with the exception that the pyrgeometer detector-temperature battery ( 1.35 volts) should be changed at 6 -month intervals. 


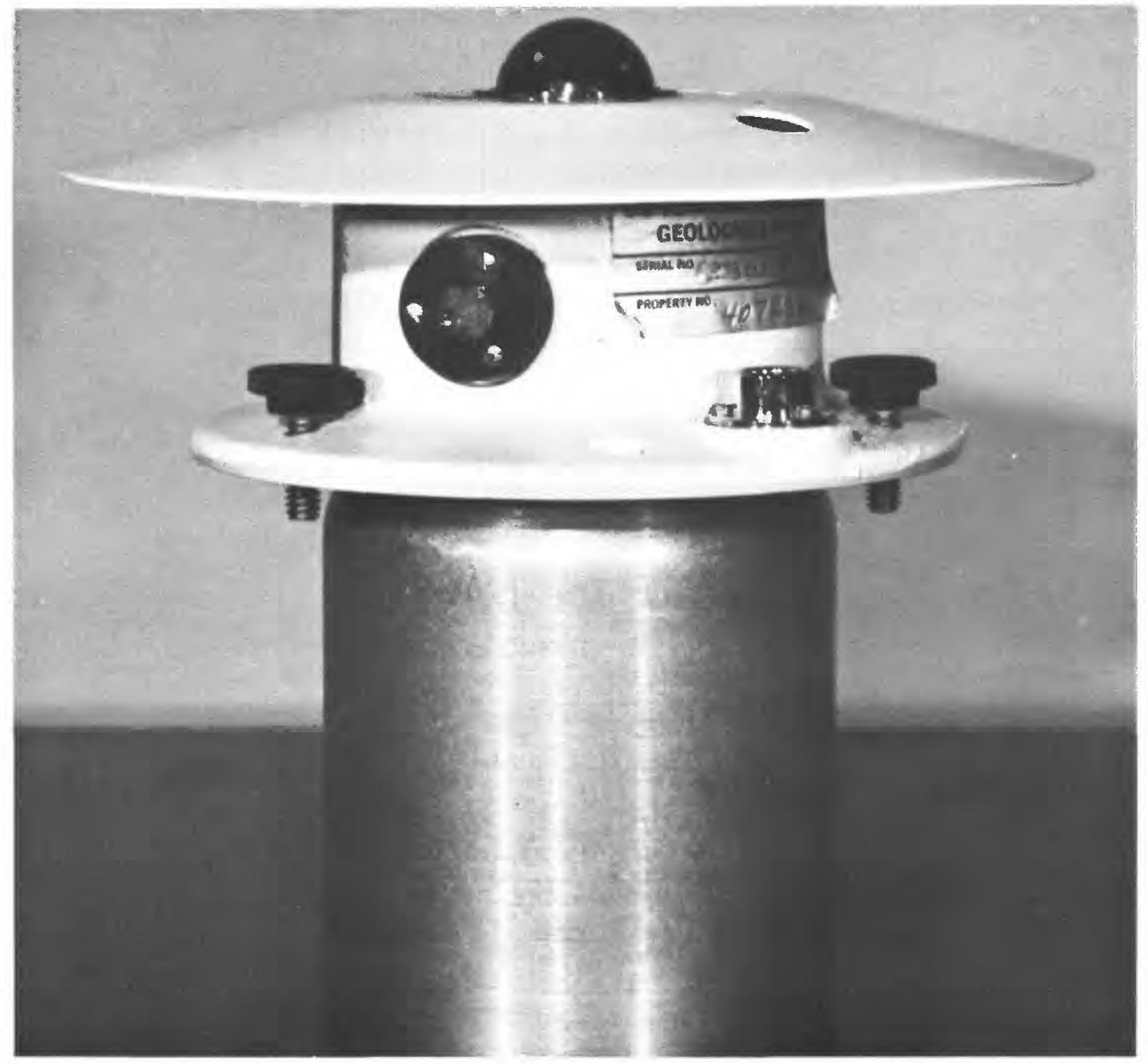

Figure 3. Eppley PIR showing silicone hemisphere, guard disc, desiccator, spirit level, and leveling screws.

To maintain the highest measurement accuracy, both the pyranometer and pyrgeometer should be returned to the factory once a year to verify their calibration.

\section{Reflected Long-Wave Radiation}

The reflectivity coefficient of a water surface for incoming long-wave radiation is approximately 3 percent as determined by the measurements of P. J. Robinson and J. A. Davies (1972). The reflected long-wave radiation is computed as the product of incoming long-wave radiation and the reflectivity coefficient. 
The long-wave radiation emitted by a body of water is dependent on the temperature and emissivity of the water at the surface, and is computed using the Stefan-Boltzmann law for black-body radiation with an emissivity of 0.97 (Robinson and Davies, 1972).

The temperature of the water surface is measured at the raft station using an epoxy-coated thermistor placed just below the water surface. It is important that the thermistor be set so that it is just barely covered when the water surface is smooth, and it bobs in and out of the water when the surface become choppy.

Because the water surface temperature is an important parameter in the energy-budget and mass-transfer studies, an analog water temperature recorder, made by Marshalltown Manufacturing Inc., is used to obtain a backup record of the water surface temperature. This battery-operated recorder is mounted in the raft station shelter and uses a spring-wound chart drive that operates for a week without attention. At weekly visits to the raft station to change the surfacewater-temperature analog chart, a temperature check should be made with $\pm 0.1^{\circ} \mathrm{C}$, calibrated, mercury-in-glass thermometer to determine the accuracy of the analog water-temperature record.

\section{Net Energy Advected to a Body of Water}

The net energy advected to a body of water is determined from the product of the temperature and the volume of water entering and leaving that body. Values of advected energy from the unmeasured tributary inflow resulting from storm runoff may be estimated from change in the water body elevation and the wet-bulb temperature recorded during the storm. Using the analog temperature recorder described in the previous section, water temperature is measured continuously at or near the gaging station located near the principal sources of inflow to, and outflow from, the water body. 


\section{Heat Transfer Between the Water and the Bottom Sediments}

The transfer of heat between bottom sediments and water is considered negligible for lakes and reservoirs with depths greater than 100 feet. However, in shallow water bodies where mixing by wind or therma1-induced currents can result in a range of temperature variations at the bottom, temperature measurements of the bottom sediments should be taken to determine their value. By comparing the temperature of the bottom sediments and the water layer adjacent to the bottom, the direction of heat flow between the sediments and water can be determined.

\section{Change in Energy Content of a Body of Water}

The change in energy content of a lake or reservoir is determined from thermal surveys conducted at intervals of approximately 2 weeks. During each survey, the variation of water temperature is measured from the surface to the bottom at each measuring site (the number varies from 10 to 25 depending on reservoir area) at specified depth intervals. The temperature measurements are obtained with a portable, battery-powered, Whitney model TC-5A, underwater thermometer accurate to $\pm 0.1^{\circ} \mathrm{C}$ (fig. 4). This unit uses a fast response thermistor to sense the water temperature changes in the water column. Temperatures are read directly from the meter dial or can be recorded on a 0 - to 1-milliamp recorder.

At the beginning and end of a thermal survey, the recorder readings are verified against a $\pm 0.1^{\circ} \mathrm{C}$, precision, mercury-in-glass thermometer. To obtain the incremental values for energy content of the reservoir, the energy in each specified depth interval is computed as the product of the temperature and volume of that layer; then the products are summed to give the total energy for the reservoir. At each measuring site of the thermal survey, the temperature of the bottom sediments is measured by allowing the underwater temperature probe to momentarily rest on the bottom sediments. 


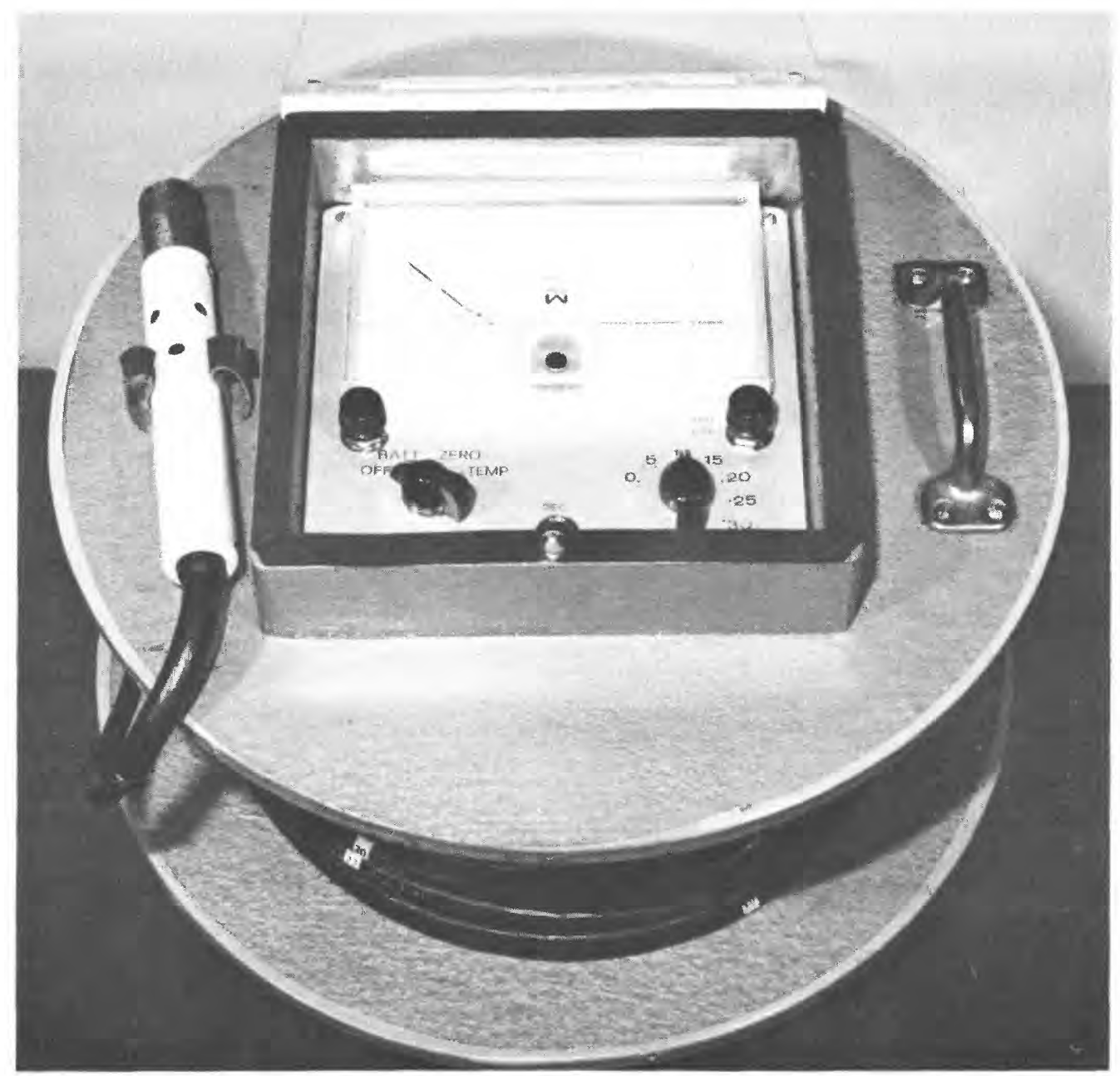

Figure 4. Whitney underwater thermometer.

\section{Vapor Pressure}

A nonventilated thermistor psychrometer is used to determine the values of wet- and dry-bulb temperatures, Tw and Ta. The psychrometer has a tetraskelion radiation shield and a large coolie hat developed for a thermocouple psychrometer by F. R. Bellaire and L. J. Anderson (1951). The tetraskelion shield shown in figure 5 is constructed with an upper and lower section to accommodate both the drybulb (upper) and wet-bulb (lower) temperature sensors. This design prevents wet-bulb cooling from affecting the dry-bulb sensor, regardles 8 of wind direction. 


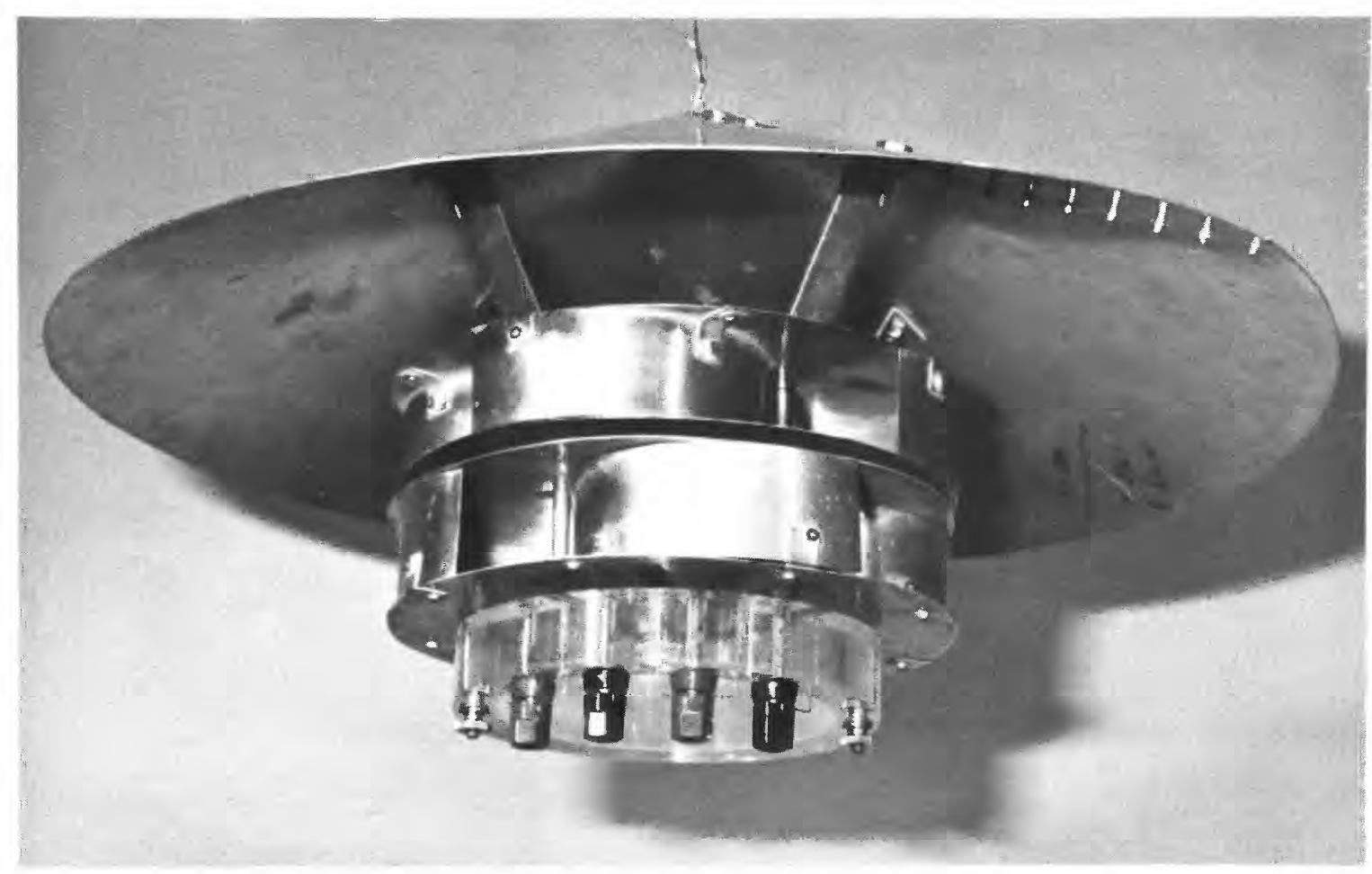

Figure 5. Complete thermistor psychrometer, with tetraskelion shield showing (top to bottom) hat, dry-bulb temperature section, wet-bulb temperature section, and reservior.

A plastic reservoir (fig. 6), which houses the temperature sensors and holds the distilled water supply for the wet-bulb temperature wick, is attached directly to the bottom of the tetraskelion shield with two wing nuts.

It is necessary to service the psychrometer at weekly intervals. At each servicing the reservoir is filled, the wick cleaned, and temperature readings from the thermistor psychrometer are compared with wet- and dry-bulb readings obtained from a power ventilated Assman psychrometer that uses mercury-in-glass thermometers. Both the wet- and dry-bulb temperatures measured by the two different psychrometers should agree within $0.50^{\circ} \mathrm{C}$. 


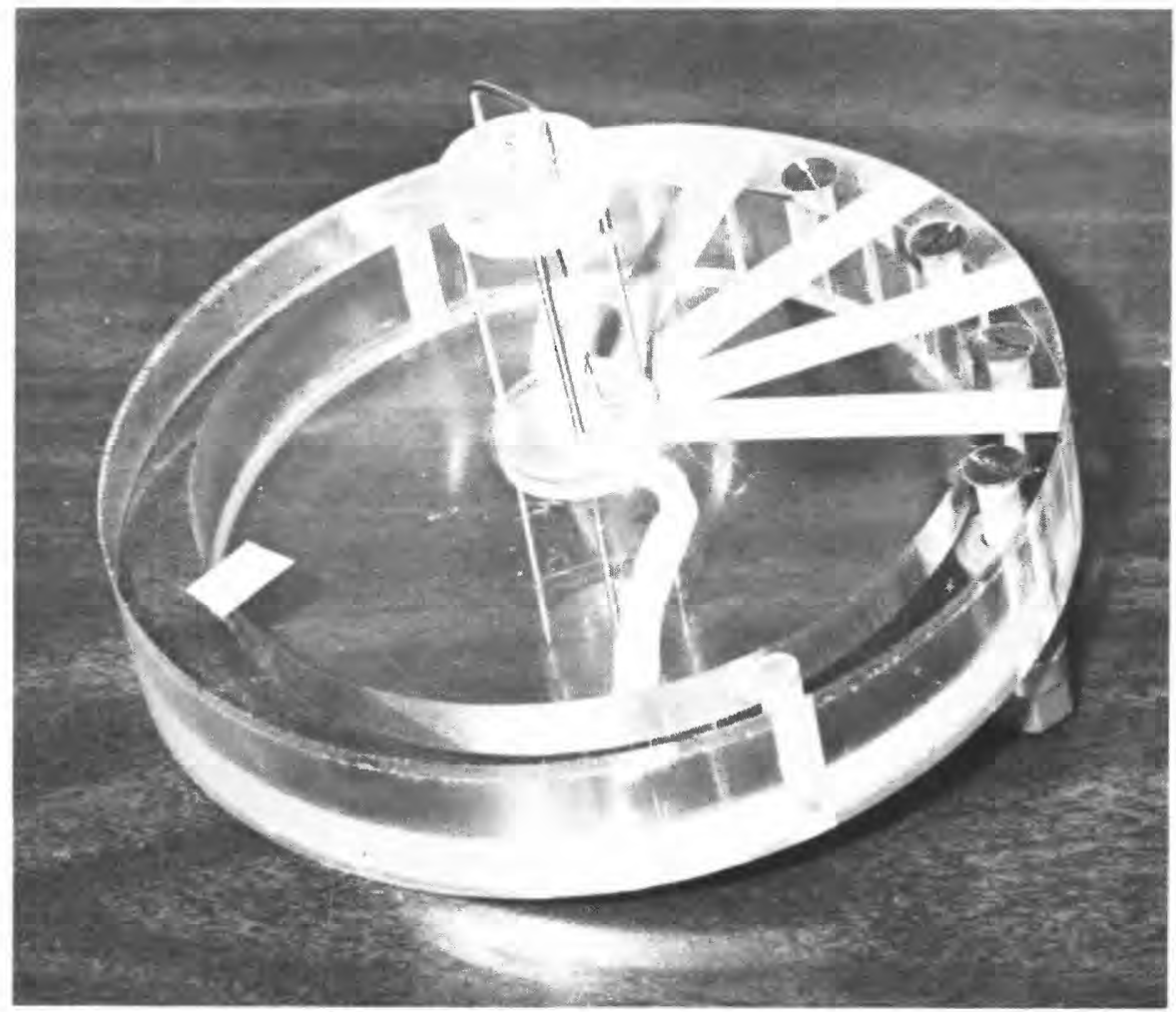

Figure 6. Psychrometer unit showing (top to bottom) dry-bulb temperature sensor, wick covering wet-bulb temperature sensor, and reservoir.

For normal operation, the psychrometers at the land and raft stations are mounted at 2-meter heights.

\section{MASS-TRANSFER INSTRUMENTATION}

Most equations for estimating evaporation by the mass-transfer method take the following form:

$$
E_{M T}=N u\left(e_{0}-e_{a}\right)
$$

where

$$
\begin{aligned}
& \mathrm{N}=\text { mass-transfer coefficient, } \\
& \mathrm{u}=\text { windspeed at some height above the water surface, }
\end{aligned}
$$




$$
\begin{aligned}
& \mathbf{e}_{0}=\begin{array}{l}
\text { vapor pressure of saturated air at the temperature } \\
\text { of the water surface, }
\end{array} \\
& \mathbf{e}_{\mathrm{a}}=\begin{array}{l}
\text { vapor pressure of the air at some height above the } \\
\text { water surface. }
\end{array}
\end{aligned}
$$

The units used in equation 3 have $E_{M T}$ expressed in inches per day, $u$ expressed in miles per hour, and $e_{o}$ and $e_{a}$ expressed in millibars.

The mass-transfer method has the advantage of lower costs and fewer instruments in relation to the energy-budget method, but this advantage can be lost if the value of $\mathrm{N}$ is not known with reasonable accuracy.

In current evaporation studies, instrumentation for both the energy-budget and mass-transfer methods are run concurrently, and the Nvalue is determined by establishing a linear relationship between the energy-budget evaporation and the mass-transfer product, $u\left(e_{0}-e_{a}\right)$.

After the $\mathrm{N}$-value has been established, the energy-budget instruments are moved to another site and evaporation is determined using the above equation.

The instruments used to determine the vapor pressure of saturated air, the thermistor that measures water surface temperature, the vapor pressure of the air, and the thermistorized wet- and drypsychrometer have been discussed in the energy-budget section of this report. In place of the second thermistorized psychrometer used at the land station for energy-budget studies, a hygrothermograph is installed on or near the shore to serve as backup for the raft psychrometer used for mass-transfer studies. The hygrothermograph utilized in these studies, made by the Belfort Instrument Co., uses a liquid-filled 
Bourdon tube and a human-hair element to sense air temperature and relative humidity, respectively. The unit is powered by an 8-day, spring-wound clock geared to the chart drive through an appropriate pair of time-scale gears. A 7-day, 2-channel chart is used to record the ink traces of the dual sensing elements for air temperature and relative humidity. The hygrothermograph is housed in a medium-standard, cottonregion-type shelter.

At weekly visits to the site, the readings from the hygrothermograph are compared with readings from an Assman psychrometer to check the accuracy of the record. If it is necessary to adjust the sensors in the field, procedures described in the manufacturer's brochure should be followed and the results noted on the chart. The hygrothermograph calibration should be checked once a year, in a constant humidity chamber, by the manufacturer or at a qualified laboratory.

\section{Windspeed}

Currently, four cup-type anemometers are being used to determine windspeed in lake and reservoir evaporation studies. The first is a Gill 3-cup anemometer, made by $R$. M. Young Co., that utilizes a d.c. tachometer generator whose analog output-voltage is directly proportional to windspeed. It can be connected to any of seven analog channels on the micrologger. The second anemometer is also manufactured by R. M. Young. This unit uses the same housing and 3-cup arrangement as the generator type described above, but uses a photo-chopper transducer circuit that provides a 4-vo1t, square-wave output whose frequency is directly proportional to windspeed. This circuit requires a 5-volt, d.c. input signal, thus a 12-volt battery with a power regulator is supplied for its operation. This anemometer is used when a11 analog channels are filled and additional windspeed data are needed at a raft station. Leads from this anemometer must be connected to channe1 8 of the micrologger. Both the photo-chopper and generator type anemometers operate through a windspeed range from 0 to $112 \mathrm{mi} / \mathrm{h}$, respectively. The third anemometer is a 3-cup unit, made by Met One, that uses a sealed, magnetic reed switch to produce a series of contact closures at a rate 
proportional to the windspeed. As with the photo-chopper above, this anemometer can only be installed at channel 8 of the micrologger. It does not require any external power supply, and has a 0 - to $100-\mathrm{mi} / \mathrm{h}$ range with a starting threshold value of $1.00 \mathrm{mi} / \mathrm{h}$. The fourth unit is a 3-cup, totalizing anemometer, manufactured by Belfort Instrument Co., that measures wind passage to the nearest tenth of a mile with a 5-digit, mechanical odometer directly coupled to the anemometer's gear system. This anemometer serves as a backup instrument for the measurement of windspeed with a range of 0 to $100 \mathrm{mi} / \mathrm{h}$ and a starting threshold of $2.0 \mathrm{mi} / \mathrm{h}$. The odometer is read at each visit to the raft station, and the difference between the readings is used to compute the average windspeed during the period between readings.

Anemometers may be installed at 1-,2-,3-, and 4-meter levels for profile windspeed measurements (fig. 7), depending on the number of

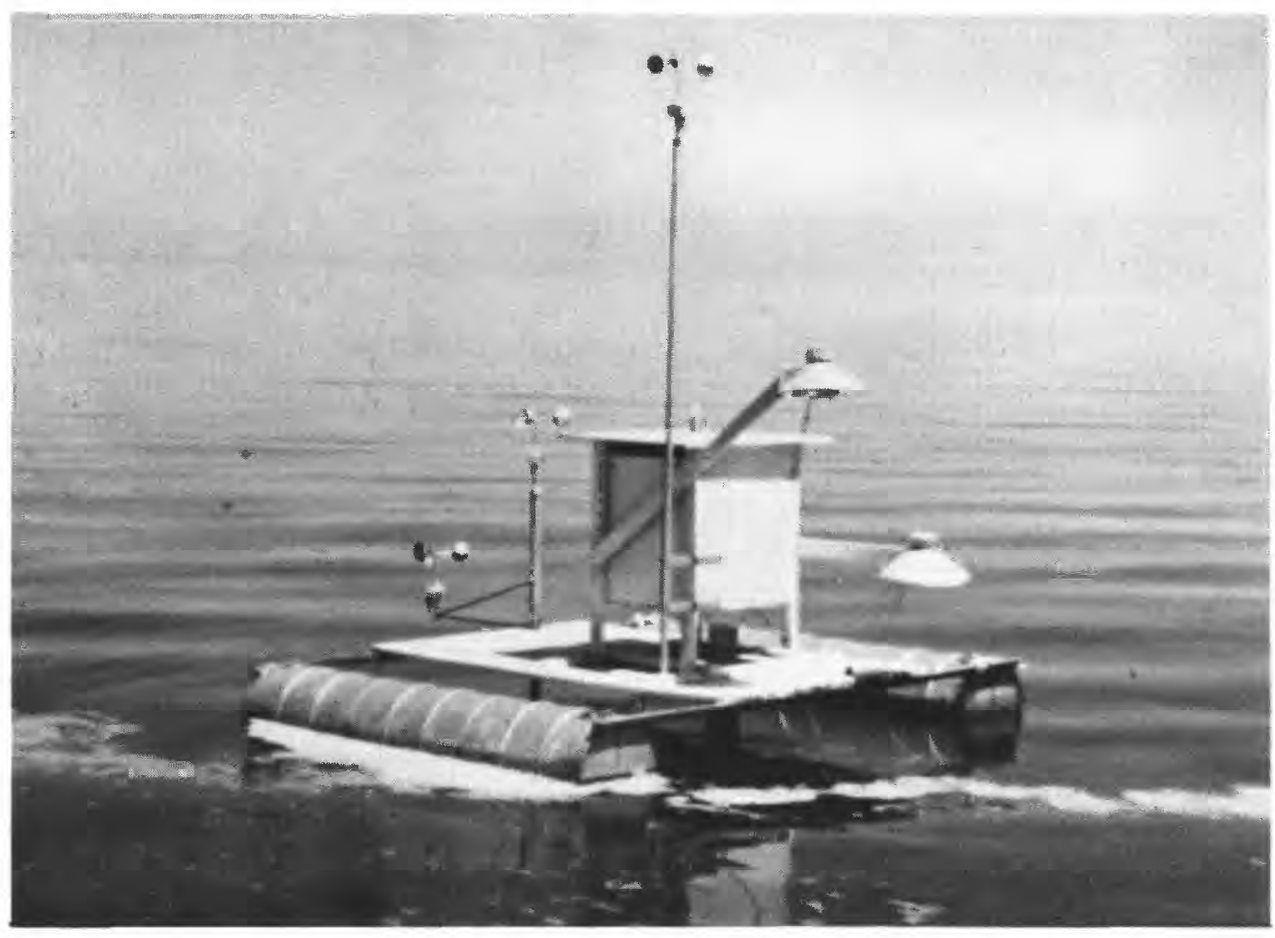

Figure 7. Raft station showing anemometers and thermistor psychrometers at multiple levels. 
channels available from the micrologger. A mast, mounted at the anchored end of the raft, supports the anemometers. Mounting the anemometers at this position ensures that they will be on the upwind side of the raft, and that no blockage will occur from the raft instrument shelter. The windspeed at each level is recorded hourly on the printer and the printout should be checked to ensure that the highest-level anemometer shows the largest average value. If malfunctions occur, the units are removed and replaced with spares kept at the project office.

The anemometers are calibrated, at the beginning and end of the open-water season for each study site, using a synchronous motor calibration unit, or by direct measurement in a wind tunnel. 


\section{REFERENCES}

Anderson, E. R., 1954, Energy-budget studies, in water-1oss investigations--Lake Hefner studies, Technical report: U.S. Geological Survey Professional Paper 269, p. 71-119.

Bellaire, F. R., and Anderson, L. J., 1951, A thermocouple psychrometer for field measurements: America Meteorological Society Bulletin v. 32 , no. 6 , p. 217-220.

Koberg, G. E., 1964, Methods to compute long-wave radiation from the atmosphere and reflected solar radiation from a water surface: U.S. Geological Survey Professional Paper 272-F, 29 p.

Robinson, P. J., and Davies, J. A., 1972, Laboratory determinations of water surface emissivity: Journal of Applied Meteorology, v. 11, p. 1,391-1,393. 